\title{
Çok Duvarıı Karbon Nanotüp Katkılı Poliamit 6 Polimerinin Termal, Termo-Mekanik Ve Tribolojik Özelliklerinin İncelenmesi
}

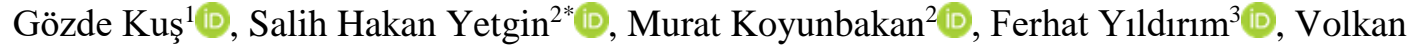 \\ Eskizeybek $^{4}\left(\mathbb{D}\right.$, Abdurrahman Genç ${ }^{1}(\mathbb{D})$
}

\author{
${ }^{1}$ Dumlupınar Üniversitesi, Fen Bilimleri Enstitüsü, İleri Teknolojiler ABD, KÜTAHYA \\ ${ }^{2 *}$ Dumlupınar Üniversitesi, Simav Teknoloji Fakültesi, Makine Mühendisliği Bölümü, Simav/KÜTAHYA \\ ${ }^{3}$ Çanakkale Onsekiz Mart Üniversitesi, Biga Meslek Yüksekokulu, Makina ve Metal Tek Böl, ÇANAKKALE \\ ${ }^{4}$ Çanakkale Onsekiz Mart Üniversitesi, Mühendislik Fakültesi, Malzeme Bil. ve Müh. Böl, ÇANAKKALE
}

Geliş / Received: 04/02/2020, Kabul / Accepted:25/12/2020

\begin{abstract}
Öz
Bu çalışmada, çok duvarlı karbon nanotüp (ÇDKNT) katkısının Poliamit 6 (PA6) nanokompozitlerin termal, termo-mekanik ve tribolojik özelliklere etkisi incelenmiştir. ÇDKNT katkılı PA6 nanokompozit granüller çift vidalı ekstruder ile üretilmiştir. Elde edilen granüllerden enjeksiyonla kalıplama tekniği kullanılarak standartlara uygun numuneler üretilmiştir. PA6 nanokompozitlerin ergime sıcaklığı ve kristallenme oranı diferansiyel taramalı kalorimetre (DSC) analizi ile depolama modülü ve kayıp modülü ise dinamik mekanik analiz (DMA) ile belirlenmiştir. Aşınma testleri kuru ortam şartları altında çelik diske karşı pim-disk sistemi ile gerçekleştirilmiştir. Çalışma sonucunda, ÇDKNT katkılı PA6 polimerinin ergime sıcaklığı sabit kalırken kristallenme oranı artmıştır. Artan ÇDKNT miktarına bağlı olarak PA6 kompozitlerin depolama modülü ve kayıp modülü artmıştır. Uygulanan yükün 10 N'dan 40 N'a artması ile katkısız PA6 polimerinin sürtünme katsayısı \%62,5 oranında artarken, PA6 nanokompozitlerin sürtünme katsayıları sırasıyla \%41,3; \%34,6; \%45,4 oranında artmıştır. Genel olarak, PA6 ve PA6 nanokompozitleri için aşınma oranı $10^{-13}-10^{-14} \mathrm{~m}^{2} / \mathrm{N}$ elde edilmiştir. En yüksek aşınma oranı 2,5 $\times 10^{-13} \mathrm{~m}^{2} / \mathrm{N}$ değeri ile katkısız PA6 polimerinde elde edilirken en düşük

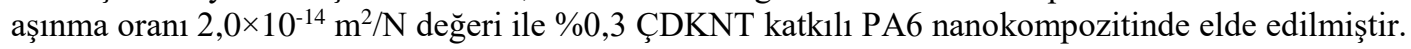

Anahtar Kelimeler: Poliamit 6, Çok duvarlı karbon nanotüp, DSC, DMA, Triboloji

\section{The Investigation of Thermal, Thermo-Mechanical and Tribological Properties of Multi-Walled} Carbon Nanotube filled Polyamide 6 polymer

\begin{abstract}
In this study, the effects of multi-walled carbon nanotube (MWCNT) on thermal, thermo-mechanical and tribological properties of Polyamide 6 (PA6) nanocomposites were investigated. MWCNT filled PA6 nanocomposite granules are produced with twin screw extruder. And then, test specimens were produced using the injection molding technique. Melting temperature and crystallization ratio were determined by differential scanning calorimetry (DSC) analysis and also storage modulus and loss modulus were determined by dynamic mechanical analysis (DMA) of PA6 nanocomposites. Wear tests were carried out under dry conditions against steel disc with using pin-on-disc device. As a result of this study, the crystallization ratio increased while the melting temperature remained stable for PA6 nanocomposites. Storage modulus and loss modulus of PA6 nanocomposites increased with the MWCNT amount. As the applied load increased from $10 \mathrm{~N}$ to $40 \mathrm{~N}$, the coefficient of friction of unfilled PA6 and PA6 nanocomposites increased by an average of $62.5 \% ; 41.3 \%$; $34.6 \% ; 45.4 \%$, respectively. The specific wear rate for unfilled PA6 and PA6 nanocomposites is in the order of $10^{-13}-10^{-14} \mathrm{~m}^{2} / \mathrm{N}$. The highest wear rate is for unfilled PA6 with a value of $2.5 \times 10^{-13} \mathrm{~m}^{2} / \mathrm{N}$ and the lowest wear rate is for $0.3 \%$ MWCNT filled PA6 nanocomposites with a value of $2.0 \times 10^{-14} \mathrm{~m}^{2} / \mathrm{N}$.

Keywords: Polyamide6, Multi-walled carbon nanotube, DSC, DMA, Tribology
\end{abstract}




\section{Giriş}

Karbon nanotüpler (KNT), benzersiz atomik yapıları, yüksek boy/en oranı, yüksek dayanım/ağırlık oranı ve mükemmel mekanik özellikleri (elastiklik modülü: 1-2 TPa, çekme dayanımı: $200 \mathrm{GPa}$ ), üstün termal özellikleri (vakum veya inert atmosferde termal olarak $2800{ }^{\circ} C^{\prime}$ ye kadar kararlı) ve yüksek elektriksel özellikleri (elmastan iki kat daha yüksek termal iletkenlik ve elektrik akım taşıma kapasitesi bakır çubuklardan 1000 kat daha yüksek) nedeniyle son y1llarda gerek bilimsel alanda gerekse endüstri alanında dikkat çekmektedir. KNT'ler bu özellikleri ile kompozit malzeme dünyasında ideal bir katkı elemanı olarak yeni bilimsel ve teknolojik firsatlar sunmaktadır.

Son y1llarda, birçok polimer türü KNT/polimer nanokompozitlerin hazırlanmasında matris malzemesi olarak kullanılmıştır. $\mathrm{Bu}$ polimer türleri içerisinde, yar1-kristal bir polimer olan Poliamit 6 (PA6) polimeri, yüksek dayanım/ağırlık oran1, kendinden yağlamalı özelliği, iyi sönümleme özelliği, korozyon direnci, UV ve gama radyasyon direnci ve oldukça basit ve ekonomik üretim prosesi nedenleriyle havac1lık, otomotiv, elektronik ve kimya endüstrisinde geniş bir şekilde kullanılmaktadır. Ancak, PA6 polimerinin yüksek nem emme, düşük boyutsal kararlılık, düşük 1sıl bozunma sıcaklığı, düşük sıcaklıkta zayıf darbe mukavemeti, kolay tutuşma ve kuru kayma koşullarında yüksek sürtünme katsayısı gibi bazı dezavantajları vardır [Aparna, 2018; Hongfu, 2016; Kumar, 2016; Jian, 2011; Hyo Jin, 2014; Duxin, 2013; Yisha, 2017]. PA6 polimerinin mekanik, termal ve tribolojik özelliklerini geliştirmek için en etkili yöntemlerden birisi takviye elamanı olarak KNT'lerin kullanılmasıdır.
$\mathrm{Bu}$ çalışmada da farklı oranlarda ÇDKNT katkılı PA6 polimeri ekstrüzyon ve enjeksiyon yöntemleri kullanılarak üretilmiştir. PA6 polimerine ilave edilen KNT katkının, ergime sıcaklığı ve kristallenme oranına etkisi DSC analizi ile, depolama ve kayıp modülleri üzerine etkisi DMA analizi ile ve sürtünme katsayısı ve aşınma oranı üzerine etkisi ise aşınma testleri ile belirlenmiştir.

\section{Deneysel Çalışmalar}

$\mathrm{Bu} \mathrm{Bu}$ çalışmada, matris malzemesi olarak ekstrüzyon ve enjeksiyon kalıplamaya uygun NYLEM $^{\circledR} 6$ (EMAŞ A.Ş. Bursa/Türkiye) kodlu poliamit 6 polimeri, takviye elemanı olarak ise Detsan A.Ş. (Türkiye) firmasından temin edilen çok duvarlı karbon nanotüp (ÇDKNT) kullanılmıştır. ÇDKNT, \% 97'den daha yüksek oranda saflığa sahiptir. Seçilen ÇDKNT'lerin ortalama dış çapı 10-20 nm, uzunluğu $10-30 \mu \mathrm{m}$ ve yüzey alanı $>200$ $\mathrm{m}^{2} / \mathrm{g}$ 'dır. Ekstrüzyon prosesi öncesinde nemi almak için PA6 polimeri ve ÇDKNT, 100 ${ }^{\circ} \mathrm{C}$ 'de ve 4 saat boyunca kurutulmuştur. ÇDKNT katkılı PA6 nanokompozit granüllerin üretimi 6 adet 1sıtma bölgeli, 22 mm vida çapına sahip ve L/D oranı 32 olan çift vidalı ekstruder kullanılarak gerçekleştirilmiştir. Üretim esnasında ekstrüzyon vidası boyunca uca doğru sicaklık dağ 11 ımı 220-230-235-240-245-245 ${ }^{\circ} \mathrm{C}$ olarak seçilmiştir. PA6 polimeri içerisine ağırlıkça \% $0,1,0,2$ ve 0,3 oranlarında ÇDKNT katılarak PA6 nanokompozit granüller üretilmiştir. Karışım üretim yöntemi ile granül haline getirilen PA6 nanokompozitler, Hastec Borche marka enjeksiyon kalıplama makinesi ile deney numunesi şeklinde kalıplanmıştır. Üretimler Gama-Alfa Plastik (Gebze) firmasında gerçekleştirilmiştir. Üretim öncesinde, PA6 nanokompozitler nemi alınması için $100{ }^{\circ} \mathrm{C}$ ve 4 saat boyunca etüv 
fırınında bekletilmiştir. Enjeksiyon kalıplama ile üretimlerde enjeksiyon vidası boyunca uca doğru 250-255-260-265-270-270 ${ }^{\circ} \mathrm{C}$ sicaklık dağılımı ve 110 bar enjeksiyon basıncı kullanılmıştır.

DSC analizleri için örnekler $30{ }^{\circ} \mathrm{C}$ 'den 350 ${ }^{\circ} \mathrm{C}$ 'ye kadar $10{ }^{\circ} \mathrm{C} / \mathrm{dak}$ hız ile 1 sitılmıştır. Katkısız PA6 polimerinin \% kristallenme oranı $\left(\mathrm{X}_{\mathrm{c}}\right)$, Eşitlik 1'de verilen formül kullanılarak hesaplanmıştır.

$\mathrm{X}_{\mathrm{c}}(\%)=\left(\Delta \mathrm{H}_{\mathrm{m}} / \Delta \mathrm{H}_{\mathrm{m}}{ }^{0}\right) \times 100$

Burada, $\Delta \mathrm{H}_{\mathrm{m}}=$ ergiyik entalpisi, $\Delta \mathrm{H}_{\mathrm{m}}{ }^{0}=$ $\% 100$ kristalin PA6 polimeri için ergiyik entalpisi 240 j/g dir (Esmizadeh vd., 2017).

Eşitlik 1 numunenin toplam ağırlığına bağlı olarak kristalin olmayan bölümleri içeren polimerin genel kristalliğini vermektedir. Doğal olarak, bu sonuç PA6 fazının kristalliğini yansıtmamaktadır. $\mathrm{Bu}$ yüzden, ÇDKNT katkılı PA6 nanokompozitlerin \% kristallenme oranlarını $\left(\mathrm{X}_{\mathrm{c}}\right)$ bulmak için Eşitlik 2'de verilen formül kullanılmıştır.

$\mathrm{X}_{\mathrm{c}}(\%)=\left(\Delta \mathrm{H}_{\mathrm{m}} / \Delta \mathrm{H}_{\mathrm{m}}{ }^{0} \times \mathrm{W}_{\text {polimer }}\right) \times 100$

Burada, $\mathrm{W}_{\text {polimer }}=$ polimer matrisin ağırlık oranidir.

TS-EN-ISO-11357-1 (ASTM D 3417) standardına uygun olarak diferansiyel taramalı kalorimetre analiz (DSC) testleri Çanakkale Onsekiz Mart Üniversitesi laboratuvarında bulunan DSC test cihazında yapılmıştır. Termal gravimetrik analizi (TGA), analizleri $20 \mathrm{ml} /$ dak. akış hızında azot gazı ortamında ve 1sitma hizı $10,0{ }^{\circ} \mathrm{C} /$ dak olacak şekilde $30-800 \quad{ }^{\circ} \mathrm{C}$ arasında gerçekleştirilmiştir. Deneyler sonucunda polimerlerin bozunma sicaklığ $1{ }^{\circ} \mathrm{C}$ olarak ve bozunma sıcaklığındaki kütle kaybı yüzde (\%) olarak verilmişstir. TGA analizleri,
Çanakkale Onsekiz Mart Üniversitesi laboratuvarında bulunan TGA test cihazında yapılmıştır. Dinamik Mekanik Analiz (DMA) testleri, Perkin Elmer marka DMA 8000 model cihazı ile $1 \mathrm{~Hz}$ frekans $1 \mathrm{~mm}$ Strain değerinde $30{ }^{\circ} \mathrm{C}$ 'den $130{ }^{\circ} \mathrm{C}^{\prime}$ ye $3{ }^{\circ} \mathrm{C} / \mathrm{dk}$ artış hızında yapılmıştır. DMA analizleri Çanakkale Onsekiz Mart Üniversitesi'nde gerçekleşmiştir.

Aşınma-sürtünme deneyleri, Kütahya Dumlupınar Üniversitesi Simav Teknoloji Fakültesi bünyesinde bulunan ve Şekil 1'de resmi verilen pim-disk aşınma cihazı kullanılarak gerçekleştirilmiştir. Aşınma deneyleri için, çekme testi numuneleri karş1 disk olarak ise Ç1040 çeliği kullanılmıştır. Deneyler kuru kayma şartları altında gerçekleştirilmiştir. Sürtünme katsayısı yanal kuvvetin, normal uygulanan kuvvete oran1 olarak ifade edilir ve Eşitlik 3'te belirtilen formül kullanılarak hesaplanmaktadır. Burada, $\mu$ : Sürtünme katsayısını, $F_{s}$ : Yanal sürtünme kuvveti $(\mathrm{N}), \mathrm{F}_{\mathrm{n}}$ : Normal kuvveti $(\mathrm{N})$ ifade etmektedir.

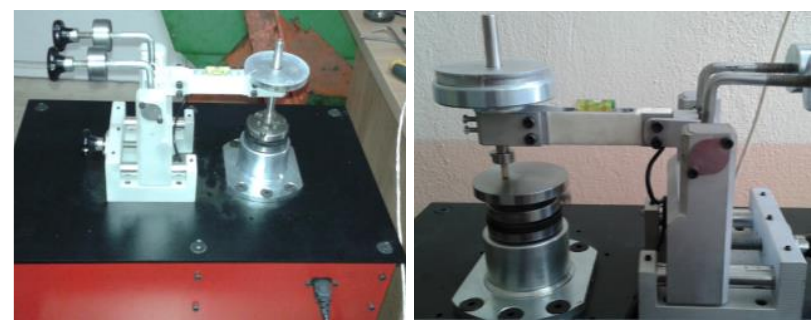

Şekil 1. Pim-disk aşınma cihazı.

$\mu=\frac{F_{s}}{F_{n}}$

Deneylerde 10; 20; 30 ve 40 N olmak üzere 4 farklı yük ile 0,$4 ; 0,8 ; 1,2$ ve 1,6 m/sn olmak üzere 4 farklı kayma hızı kullanılmıştır. Kayma mesafesi olarak $2000 \mathrm{~m}$ belirlenmiştir. Her testten önce $\left(m_{1}\right)$ ve sonra $\left(m_{2}\right)$ numune ağırlıkları ölçülmüş ve ağırlık kaybı $(\Delta \mathrm{m})$ tespit edilmiştir ve Eşitlik 4'te verilen formül 
ile spesifik aşınma oranları

hesaplanmıştır.

$$
K_{o}=\frac{\Delta_{m}}{L^{*} \rho^{*} F}
$$

Burada; $\Delta \mathrm{m}$ : Ağırlık kaybı (g), L: Kayma mesafesi (m), $\rho$ : Malzemelerin yoğunluğu $\left(\mathrm{g} / \mathrm{cm}^{3}\right), \mathrm{F}$ : Uygulanan yük $(\mathrm{N})$.

\section{Deneysel Sonuçlar}

\subsection{Diferansiyel taramalı kalorimetre (DSC) sonuçları}

Amorf fazın yanı sıra, yarı kristal özelliğe sahip poliamit 6 polimerinde, kararlı monoklinik $\alpha$-formu, metastabil pseudoheksagonal $\beta$-formu ve kararsiz monoklinik $\gamma$-formu olmak üzere üç ana kristalin form oluşabilmektedir. $\alpha$-fazında, zincirler anti-paralel bir şekilde düzenlenmiş genişletilmiş konfirmasyonda iken, $\gamma$-fazında zincirlerinde paralel düzenleme ve zincirler üzerindeki -NH grupları düzlemsel genişletilmiş konfirmasyondan yaklaşık $60^{\circ}$ döndürülür. Şekil 2'de katkısız PA6 polimeri ve PA6 nanokompozitlere ait endotermik termogram sonucu verilmiştir. Tablo 1'de ise bu termogram kullanılarak elde edilen ergime sıcaklığ1, ergime entalpisi, camsı geçiş sıcaklığ1 ve \% kristallik değerleri verilmiştir. PA6 polimerine ilave edilen ÇDKNT ile PA6 polimerinin ergime sıcaklığ $225{ }^{\circ} \mathrm{C}$ civarında sabit kalırken kristallenme oranının $\operatorname{arttığ} 1$ belirlenmiştir. ÇDKNT katkılı polimer malzemelerin ergime sıcaklığ ve kristallenme oranları üzerine farklı çalışmalar mevcuttur. $\mathrm{Bu}$ çalışmalarda, artan ÇDKNT miktarına bağlı olarak ergime sıcaklığı ve kristallenme oranlarının sabit kaldığı, azaldığı veya hafif bir şekilde arttığı belirtilmiştir.
Tablo 1. Endotermik DSC sonuçlarına göre numunelerin ergime sicaklığg, camsı geçiş sicaklığ 1 ve kristallenme oranları.

\begin{tabular}{|l|c|c|c|c|}
\hline \multirow{2}{*}{ Numune } & $\begin{array}{c}\text { Ergime } \\
\text { sıcaklığı, } \\
\left({ }^{\circ} \mathrm{C}\right)\end{array}$ & $\begin{array}{c}\text { Ergime } \\
\text { entalpisi, } \\
(\mathrm{J} / \mathrm{g})\end{array}$ & $\begin{array}{c}\text { Camsı geçiş } \\
\text { sicaklığ }, \\
\left({ }^{\circ} \mathrm{C}\right)\end{array}$ & $\begin{array}{c}\% \\
\text { Kristallik }\end{array}$ \\
\cline { 2 - 5 } $\mathrm{T}_{\mathrm{m}}$ & $\Delta \mathrm{H}_{\mathrm{m}}$ & $\mathrm{T}_{\mathrm{g}}$ & $\mathrm{X}_{\mathrm{c}}$ \\
\hline PA6 & 225,5 & 59,4736 & 43,26 & 24,78 \\
\hline $\begin{array}{l}\text { PA6-\%0,1 } \\
\text { ÇDKNT }\end{array}$ & 224,8 & 60,1268 & 48,41 & 25,07 \\
\hline $\begin{array}{l}\text { PA6-\%0,2 } \\
\text { ÇDKNT }\end{array}$ & 225,1 & 68,2992 & 59,94 & 28,51 \\
\hline $\begin{array}{l}\text { PA6-\%0,3 } \\
\text { ÇDKNT }\end{array}$ & 225,1 & 60,7643 & 60,26 & 25,39 \\
\hline
\end{tabular}

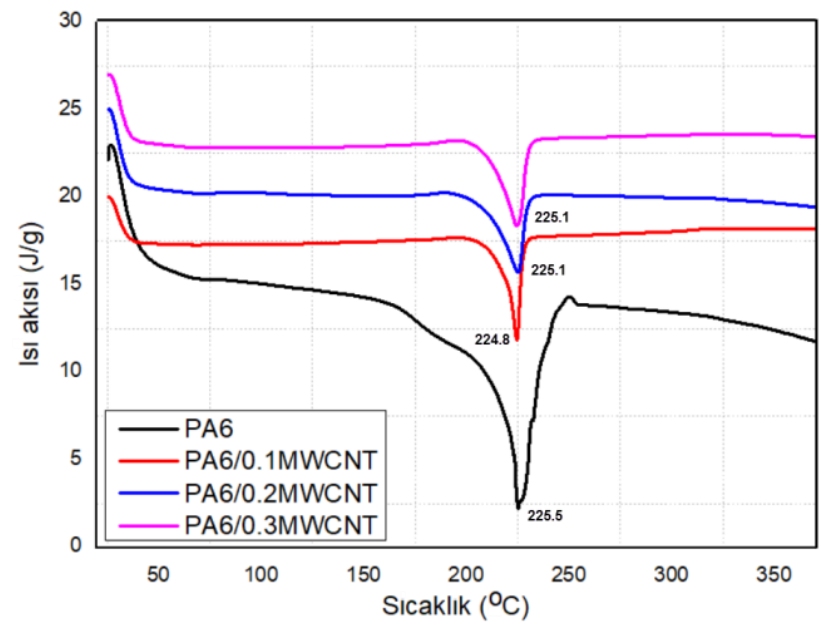

Şekil 2. PA6 ve ÇDKNT katkılı PA6 nanokompozitlerin ergime (endotermik) termogramları.

Mahmood ve arkadaşlarının (2013), yaptı ğ çalışmada, ÇDKNT katkılı PA6 nanokompozitlerin ergime sicaklığının arttığı belirtilmiştir. Polimer matris içerisinde ÇDKNT katkının bulunmasının PA6 zincirlerinin hareketini kısıtladığı, dolayısıyla PA6-\%0,5KNT nanokompozitin ergime sicaklığının yaklaşık $\quad 17 \quad{ }^{\circ} \mathrm{C} \quad \operatorname{arttığ~}$ belirtilmiştir. Aynı zamanda, ergiyik ekstrüzyon yöntemi ile karşılaştırıldığında, proses süresince polimer yapısına zarar vermediği için solüsyon karıştırma yönteminin çekirdeklenmeyi ve daha az kararlı olan $\gamma$-formuna göre $\alpha$-formunun oluşumunu desteklediği ve sonuç olarak kristallanme sıcaklığının arttığı belirtilmiştir. 
Ayrıca, karbon nanotüplerin (modifiyeli veya modifiyesiz) çekirdeklenme alanları oluşturarak PA6 polimerinin kristallenme özelliklerini geliştirdiği belirtilmiştir. PA6 numunelerin ergime sicaklığının artan ÇDKNT miktarına bağlı olarak azalarak, 220 ${ }^{\circ} \mathrm{C}$ civarında elde edildiğini belirtmişlerdir. $\mathrm{Bu}$ durumun, kristallerin boyutunun küçük olduğunun veya oldukça az sayıda düzenli paketlenmenin oluşmasıyla meydana geldiğini belirtmişlerdir. PA6 polimerinin $\% 24,78$ olan kristallenme oran $1 \% 0,1 ; \% 0,2$ ve $\% 0,3$ oranlarında ÇDKNT ilave edilmesi ile sirasiyla $\% 25,07 ; \% 28,51$ ve $\% 25,39$ oranlarında elde edilmiştir. Marini ve Suman (2017), montmorillonite (MMT) katk111 PA6 nanokompozitlerin kristallenme özelliklerini inceledikleri çalışmada, modifiye edilmemiş PA6/MMT nanokompozitlerin sabit şartlar altında katkısız PA6 polimerinden daha yüksek kristallenme oranına sahip olduğunu, diğer yandan modifiye edilen MMT katkı1ı PA6 nanokompozitlerin ise daha düşük kristallenme oranına sahip olduklarını belirtmişlerdir. Xu ve arkadaşlarının (2014), yaptıkları çalı̧̧mada, nano- $\mathrm{SiO}_{2}$ katkısının PA6 polimerinin ergime sicaklığını etkilemediği belirtilmiştir. Ancak, artan nano$\mathrm{SiO}_{2}$ miktarına bağlı olarak kristallenme sıcaklığının azaldığı belirtilmiştir. $\mathrm{Bu}$ durumun, PA6 moleküler zincirlerinin hareketinin nano- $\mathrm{SiO}_{2}$ katk1 tarafindan engellendiğinin bir göstergesi olduğu belirtilmiştir. Aynı zamanda, nano- $\mathrm{SiO}_{2}$ katkının kuvvetli bir heterojen çekirdeklenme kapasitesine sahip olmasından dolayı PA6 nanokompozitlerin kristallenme oranlarının PA6 polimerine göre hafif̧̧e yükseldiği de belirtilmiştir. Hassani ve arkadaşları (2013), KNT katk1l PA6 nanokompozitin kristallenme özelliklerini inceledikleri çalışmada artan KNT miktarına bağlı olarak ergime sıcaklığının arttığını belirtmişlerdir. KNT katkının polimer matris içerisinde çekirdekleyici ajan gibi davrandı̆̆ belirtilmiştir. \%0,2 KNT miktarına kadar kristallenme oranının arttığı, bu değerden sonraki KNT miktarlarında ise azaldığı belirtilmiştir. Düşük oranlarda KNT katkının çekirdekleyici ajan gibi davrandığı ancak artan KNT miktarlarında rastgele dağılan KNT katkının kristallenmeyi engellediği ve böylece kristal büyümesinin kısıtlandığı belirtilmiştir. Tablo 1 incelendiğinde PA6 polimerinin $43,2^{\circ} \mathrm{C}$ olan camsı geçiş sicaklığ artan oranlarda ÇDKNT ilave edilmesiyle sirasiyla 48,$4 ; 59,9$ ve $60,2 \quad{ }^{\circ} \mathrm{C}$ olarak bulunmuştur. PA6 polimeri içerisinde iyi dağılan nanotüplerin birbirleriyle etkileşiminin artacağı ve polimer zincirlerinin hareketini kısıtlayarak camsı geçiş sıcaklığının artacağı belirtilmiştir. Aynı zamanda, artan camsı geçiş sıcaklığının kompozitin elastiklik modülü ve çekme dayanımını artıracağı da belirtilmiștir (Mahmood vd., 2013).

Şekil 2'de verilen termogram incelendiğinde tüm numunelerin tek bir pik gösterdiği belirlenmiştir. $\mathrm{Bu}$ tek ergime piki, PA6 polimerinin sadece $\alpha$-formunda kristal yapıya sahip olduğunun bir göstergesidir. Benzer bir sonuç Mahmood ve arkadaşları (2013), tarafından yapılan çalışmada da elde edilmiştir. Hou ve arkadaşları (2013), tarafindan fonksiyonelleştirilmiş grafen katk1lı PA6 nanokompozitlerde de tek bir ergime pikinin oluştuğu, PA6 polimerinin kristallenmesi süresince çekirdekleyici ajan gibi davranan iyi dağılmış grafen plakalarının kristallenme sıcaklığını önemli oranda arttırdığı belirtilmiştir. Hassani ve arkadaşları (2013), yüksek KNT içeriğinde, KNT katkısının yüksek 1sı iletkenliğinden dolayı ergime sıcaklı̆̆ının azalacağı ve kristal parçalara 1S1 transferinin kolaylaşacağı ve dolayısıyla ergime sicaklı̆̆ının azalacağ 1 belirtilmiştir. Yapılan çalışmada, PA6 
polimerinin kaba bir pik ve $215{ }^{\circ} \mathrm{C}$ 'de $\gamma$ formunu temsil eden küçük bir pik olmak üzere iki pik oluşturduğu gözlenmiştir.

\section{2. Termal gravimetrik analiz (TGA) sonuçları}

Şekil 3'te PA6 ve nanokompozitlerin sıcaklığa bağlı olarak kütle kayıpları verilmiştir. Şekilde görüldüğü gibi PA6 polimeri ve PA6 nanokompozitler benzer bir termal bozunma davranışı göstermişlerdir. Kütle kayıpları yaklaşık olarak $350{ }^{\circ} \mathrm{C}$ 'de başlamış ve $500{ }^{\circ} \mathrm{C}^{\prime}$ de tamamlanmıştır. Araujo ve arkadaşları (2011), ağırlıkça \%3 KNT katkılı PA6 nanokompozitlerin kütle kayiplarının $\quad 400-520 \quad{ }^{\circ} \mathrm{C} \quad$ arasinda gerçekleştiğini ve PA6 ile PA6 nanokompozitlerin benzer termal davranış sergilediğini belirtmişlerdir. Mahmood ve arkadaşları (2013), saf ve fonksiyonelleştirilmiş ÇDKNT katkılı PA6 polimerinin termal özelliklerini inceledikleri çalışmada, PA6 polimeri ile karşılaştırıldığında, $\% 0,5 \quad$ oranında modifiyesiz ÇDKNT katkılı PA6 polimer nanokompozitin termal bozunma sıcaklığını $10{ }^{\circ} \mathrm{C}$ arttığını, fonksiyonelleştirilmiş ÇDKNT katkılı PA6 polimerinin ise termal özellikleri hafif bir şekilde kötüleştirdiği belirtilmiştir. Pratikte, yapısal kararsızlığın bir göstergesi olan numunelerin \%50 ağırlık kayıplarındaki bozunma sicaklığ hesaplanmalıdır. PA6 polimeri ve PA6 nanokompozitlerin \%50 kütle kaybındaki sıcaklıkları incelendiğinde, \%0,3 ÇDKNT katkılı PA6 nanokompozitlerin daha yüksek sıcaklıklarda kütle kaybına uğradığı belirlenmiştir. $\mathrm{Bu}$ durum, ÇDKNT katkılı PA6 nanokompozitlerin termal bozunma özelliklerini geliştirdiğini göstermektedir.

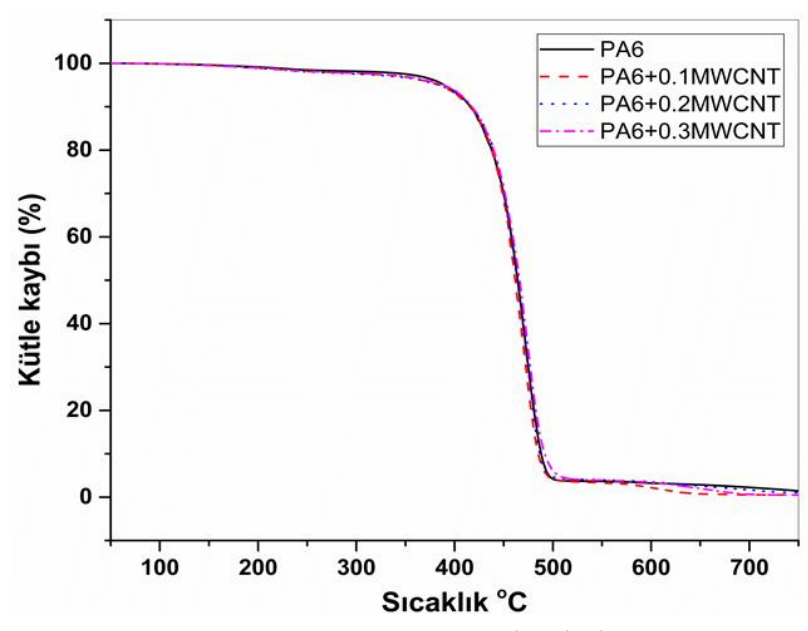

Şekil 3. PA6 ve ÇDKNT katkılı PA6 nanokompozitlerinin kütle kaybı grafiği.

\subsection{Dinamik mekanik analiz (DMA) sonuçları}

Şekil 4'te PA6 polimeri ile ÇDKNT katkılı PA6 nanokompozitlerin sıcaklığa bağlı olarak Tan $\delta$ sonuçları verilmiştir. Tan $\delta$ eğrisinin pik noktaları malzemenin camsı geçiş sıcaklığını $\left(\mathrm{T}_{\mathrm{g}}\right)$ vermektedir. Şekilde görüldüğü gibi PA6 polimerinin camsı geçiş sıcaklığ $51,4{ }^{\circ} \mathrm{C}$ elde edilirken $\% 0,1 ; \% 0,2$ ve $\% 0,3$ ÇDKNT katkılı PA6 nanokompozitlerin camsı geçiş sicaklıkları sirasıyla 50,$53 ; 52,79$ ve $53,46{ }^{\circ} \mathrm{C}$ elde edilmiştir. Esmizadeh ve arkadaşları (2017), PA6/ poli-epiklorohidrin-koetilen oksit (ECO) polimerine ilave ettikleri ÇDKNT katkının polimer zincir hareketliliğini kısıtladığı ve dolayısıyla PA6 ve ECO bileşenlerinin sönümleme performanslarının azaldığını belirtmişlerdir. KNT katk11 polimer numunelerde daha yüksek camsı geçiş sıcaklığı elde edilmekle birlikte $\tan \delta$ tepe değerlerini azalttığı belirtilmiştir. Kanapitsas ve Tsonos (2009), KNT katkılı PA6 nanokompoziti ve ÇDKNT katkıl1 Polipropilen (PP) nanokompozitinin DMA sonuçlarını inceledikleri çalışmada, PA6 polimerine ilave edilen KNT katkının depolama modülünü \%30 oranında artırdığını ancak camsı geçiş sıcaklığını azalttığını belirtmişlerdir. PP polimerine ilave edilen 
ÇDKNT katkısının ise depolama modülünü \%60 oranında artırdığını ancak camsı geçiş sıcaklığının değişmediğini belirtmişlerdir. Sorrentino ve arkadaşları (2010), Polisitren (PS) polimerine ilave ettikleri ÇDKNT katkının depolama modülünü artırdığını, camsı geçiş sıcaklığını ise ani bir şekilde azalttığını, camsı geçiş sıcaklığının artan ÇDKNT miktarı ile de artığını belirtmişlerdir. Düşük KNT miktarlarında, serbest hacmin artması ile zincir hareketliliğinin $\operatorname{arttığ1}$ ve camsı geçiş sıcaklığının azaldığı belirtilmiştir. Artan KNT miktarlarında ise polimer zincir hareketinin kısıtlanmasının arttığı ve bu durumun ise ani düşüşten sonra artan KNT miktarına bağlı olarak artan camsı geçiş sıcaklığını açıkladığı belirtilmiştir.

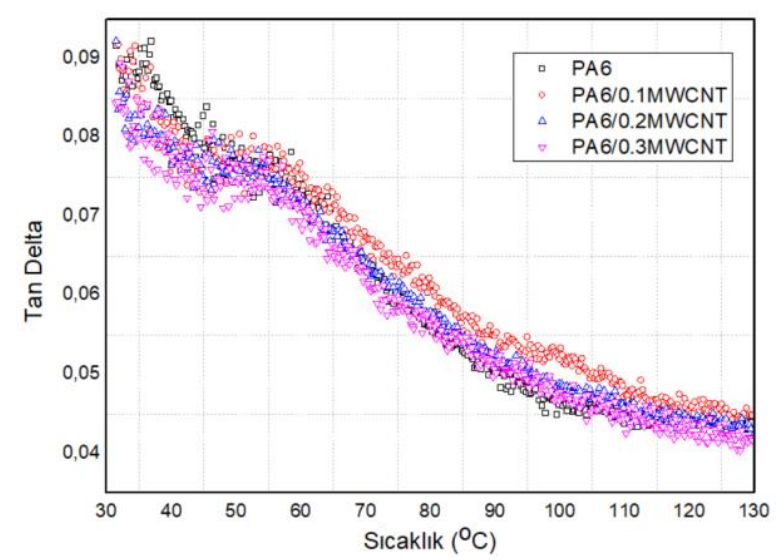

Şekil 4. PA6 ve PA6 nanokompozitlerin Tan

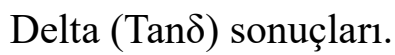

Şekil 5'te PA6 ve PA6 nanokompozitlerin sıcaklığa bağlı olarak depolama modülü değerleri verilmiştir. PA6 polimerine ilave edilen farklı oranlardaki ÇDKNT katkısı PA6 polimerinin depolama modülünü artırmıştır. Katkısız PA6 polimeri ile karşılaştırıldığında bu artışlar \%0,1; \%0,2 ve \%0,3 ÇDKNT katkılı PA6 nanokompozitleri için sirasıyla $\% 16,2$; \%3,75; \%16,1 oranlarında elde edilmiştir. Bunun karbon nanotüpün yüksek rijitliğe sahip olması ve aynı zamanda polimer zincirlerinin hareketliliğini kısıtlamasından kaynaklandığ1 belirtilmiştir (Aso vd., 2007; Szymczyk vd., 2011). Benzer bir açıklama, Jin ve arkadaşları (2001) tarafından ağırlıkça \%4-26 oranlarında ÇDKNT katkılı Poli-metilmetakrilat (PMMA) nanokompozit numuneleri için de yapılmıştır. Özellikle yüksek sıcaklıklarda KNT, yüksek rijitlik özelliğine sahip olmasının depolama modülünü artırdığı belirtilmiştir. Ayrıca, KNT katkının bulunmasının matrisin yüksek sıcaklıklarda dahi yüksek modül değerlerini sürdürmesini sağladığı belirtilmiştir.

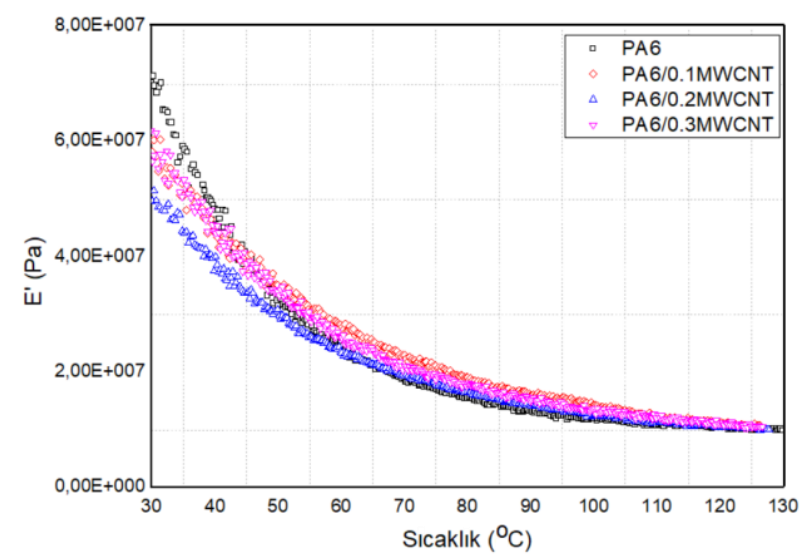

Şekil 5. PA6 ve PA6 nanokompozitlerin depolama modülü (E') sonuçları.

Liu ve arkadaşları (2004), PA6 polimerine ilave ettikleri farklı oranlardaki KNT katkıların depolama modülü sonuçlarını incelemişlerdir. Camsı bölgede $\left(0{ }^{\circ} \mathrm{C}\right), 2,08$ GPa olan PA6 polimerinin depolama modülü, \%2 KNT katkı1ı PA6 nanokompoziti için \%43 oranında artarak 2,97 GPa elde edilmiştir. Kauçuğumsu bölgede $\left(120^{\circ} \mathrm{C}\right)$ ise $350 \mathrm{MPa}$ değerinden \%57 oranında artarak $550 \mathrm{MPa}$ değerine ulaşmıştır. Depolama modülündeki artış, yüksek en/boy oranına sahip KNT katkının homojen dağılımına ve yüksek mekanik özelliklerine bağlanmıştır. Camsı geçiş sıcaklığı sonuçları incelendiğinde ise 65 ${ }^{\circ} \mathrm{C}$ civarında kaldığı belirlenmiştir. Benzer bir sonuç, Esmizadeh ve arkadaşları (2017) tarafından yapılan ağırlıkça \%1,5 oranında 
ÇDKNT katkılı PA6/OEC nanokompozitlerde de elde edilmiştir.

Şekil 6'da PA6 polimer ve PA6 nanokompozitlerin sicaklığa bağlı olarak kayıp modülü değerleri verilmiştir. Şekilden de görüldüğü gibi PA6 polimerine ilave edilen ÇDKNT katkısı kayıp modülü değerlerini artırmıştır. Bose ve arkadaşları (2008), ağırlıkça 50/50 PA6/Akrilo-nitril-bütadienstiren (ABS) polimerine ilave ettikleri ÇDKNT katkının depolama modülü ve kayıp modüllerini incelemişlerdir. ÇDKNT katkılı (PA6/ABS/ÇDKNT) polimerinde, düşük sıcaklıklarda yüksek depolama modülü elde edildiği belirtilmiştir. Ayrıca, modifiyeli ÇDKNT katkının, özellikle camsı bölgede, modifiyesiz ÇDKNT katkıya göre daha yüksek depolama modülü elde edildiğini tespit etmişler ve bunun sebebini modifiyeli KNT katkının homojen olarak dağılmasına bağlamışlardır. Depolama modülü sonuçları incelendiğinde, zincir hareketliliğini sınırlayan ÇDKNT katkının ilave edilmesi ile $\mathrm{T}_{\alpha}$ 'nın (amorf fazın camsı geçiş sıcaklı̆̆ı) hafifçe arttı̆̆ belirtilmiştir.

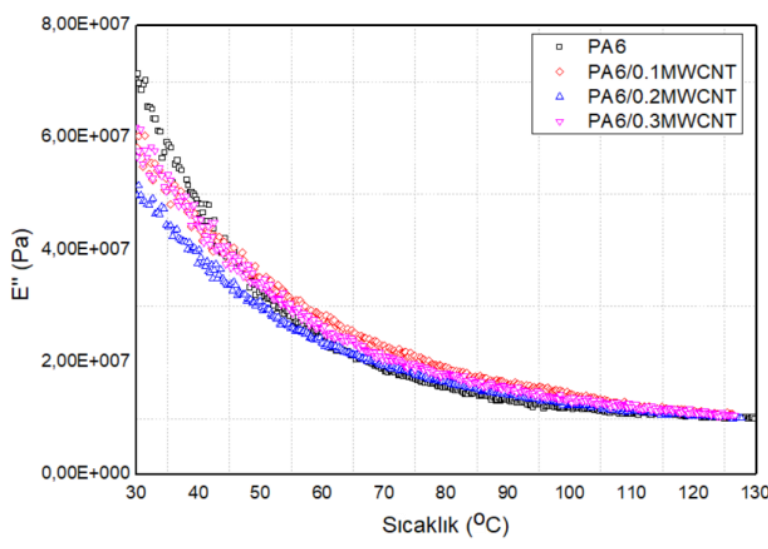

Şekil 6. PA6 ve PA6 nanokompozitlerin kayıp modülü (E") sonuçları.

\subsection{Așınma deneyi sonuçları}

Şekil 7 (a-d)'de katkısız PA6 polimeri ile $\% 0,1 ; \% 0,2 ; \% 0,3$ ÇDKNT katkılı PA6 nanokompozitlerinin, sirasıyla 0,$4 ; 0,8 ; 1,2$ ve $1,6 \mathrm{~m} / \mathrm{sn}$ kayma hızlarında, $10-40 \mathrm{~N}$ yüke karşı sürtünme katsayıları verilmiştir. Genel olarak şekiller incelendiğinde, uygulanan yükün artmasıyla, sürtünme katsayısının arttığ1 gözlenmiştir. 0,4 m/s kayma hızında uygulanan yükün $10 \mathrm{~N}$ 'dan $40 \mathrm{~N}$ 'a artması ile katkısız PA6 polimerinin sürtünme katsayısı $\% 62,5$ oranında artarken, $\% 0,1 ; 0,2 ; 0,3$ ÇDKNT katkılı PA6 nanokompozitlerin sürtünme katsayıları sirasıyla \%41,3; \%34,6; \%45,4 artmıştır. Kaştan (2015) yaptığı çalışmada artan yük ve kayma hızına bağlı olarak sürtünme katsayısının arttığını belirtmiştir. Uygulanan yüke bağl1 olarak pim ile diskin teması sonucunda 1sındığını ve bu durumun temas noktasındaki sıcaklığı arttırdığını belirtmiştir. Ayrıca artan sıcaklık ile PA6 polimerinin yumuşadığını, PA6 polimerinden küçük partiküllerin koptuğunu ve plastik deformasyonun meydana geldiğini belirtmiştir. Bunun sonucu olarak yüksek yüklerin ve hizların sürtünme katsayısında artışa neden olduğunu açıklamıştır. PA6 polimerine ilave edilen ÇDKNT katkının sürtünme katsayısı üzerindeki etkisi incelendiğinde ise artan ÇDKNT miktarına bağlı olarak sürtünme katsayısının azaldığı belirlenmiştir. 1,2 m/s kayma hızında, $30 \mathrm{~N}$ yük altında, PA6 polimerine ilave edilen $\% 0,1, \% 0,2$ ve \%0,3 oranlardaki ÇDKNT katkıs1, sürtünme katsayısını $\% 29,9 ; \% 39,8$ ve $\% 51,8$ oranında azaltmıştır. Benzer sonuçları Lee ve arkadaşları (2014), tarafindan da elde edilmiştir. Artan KNT miktarına bağlı olarak sürtünme katsayısındaki azalmayı, KNT'lerin yüksek 1sı iletkenlikleri sayesinde aşınma yüzeyindeki ısınmanın azalması olarak açıklamışlardır. Yang ve arkadaşları (2005), yaptıkları çalışmada, artan KNT miktarı ile sürtünme katsayısının azaldığını belirtmişlerdir. $\mathrm{Bu}$ durumu, KNT'lerin 
mükemmel mekanik ve tribolojik özelliklerine sahip olmasına bağlamışlardır. Uygulanan kayma hızı ve yük arasındaki en yüksek sürtünme katsayısı 1,6 m/s kayma hızı ve $40 \mathrm{~N}$ yük altında $0,7026 \mu$ değeri ile
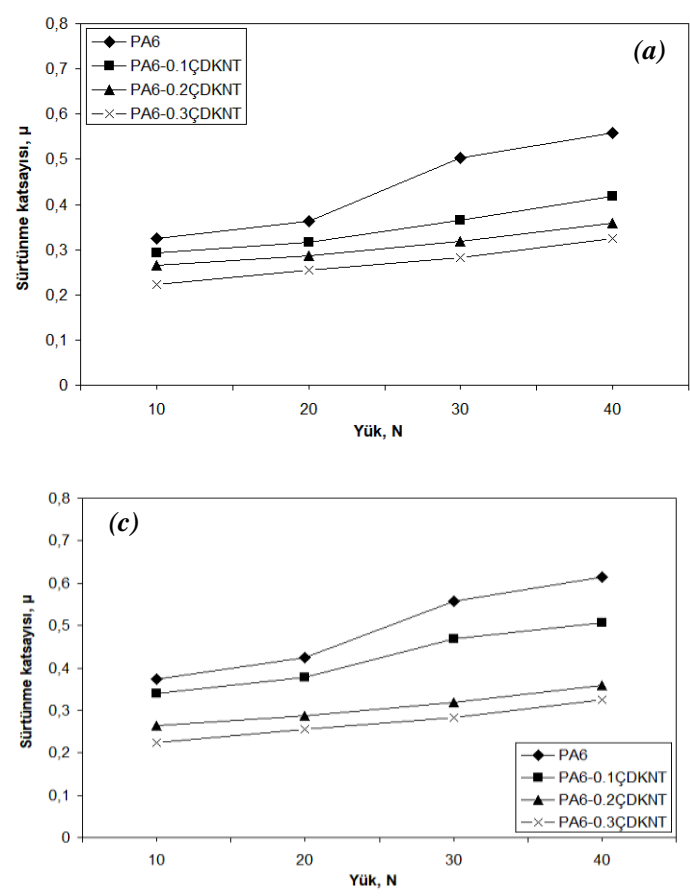

Şekil 7. PA6 ve PA6 nanokompozitlerin sürtünme katsayısı-yük ilişkisi: a) $0,4 \mathrm{~m} / \mathrm{sn}$, b) $0,8 \mathrm{~m} / \mathrm{sn}, \mathrm{c}) 1,2 \mathrm{~m} / \mathrm{sn}, \mathrm{d}) 1,6 \mathrm{~m} / \mathrm{sn}$.

Şekil 8'de katkısız PA6 polimeri ile \%0,1; $\% 0,2$ ve $\% 0,3$ ÇDKNT ilaveli PA6 nanokompozit numunelerin, $10 \mathrm{~N}, 20 \mathrm{~N}, 30 \mathrm{~N}$ ve $40 \mathrm{~N}$ yük altındaki sürtünme katsayıs1kayma hızı ilişkisi verilmiştir. Genel olarak şekiller incelendiğinde, kayma hızının artması ile sürtünme katsayısı artmıştır. Katkısız PA6 polimeri için $0,4 \mathrm{~m} / \mathrm{s}$ kayma hızında sürtünme katsayısı $0,3242 \mu$ değerindeyken hızın 4 katına çıkartılması ile \%21 artmıştır. Suresha ve arkadaşları (2010), mikro ve nano katkı1ı Poliamit 66 (PA66)/PP nanokompozitlerin mekanik ve tribolojik özelliklerini inceledikleri çalışmasında, artan kayma hızına bağlı olarak sürtünme katsayısının arttığını, tribolojik özelliklerin nano katkının eklenmesi ile geliştiğini belirtmişlerdir. PA6 polimerinin
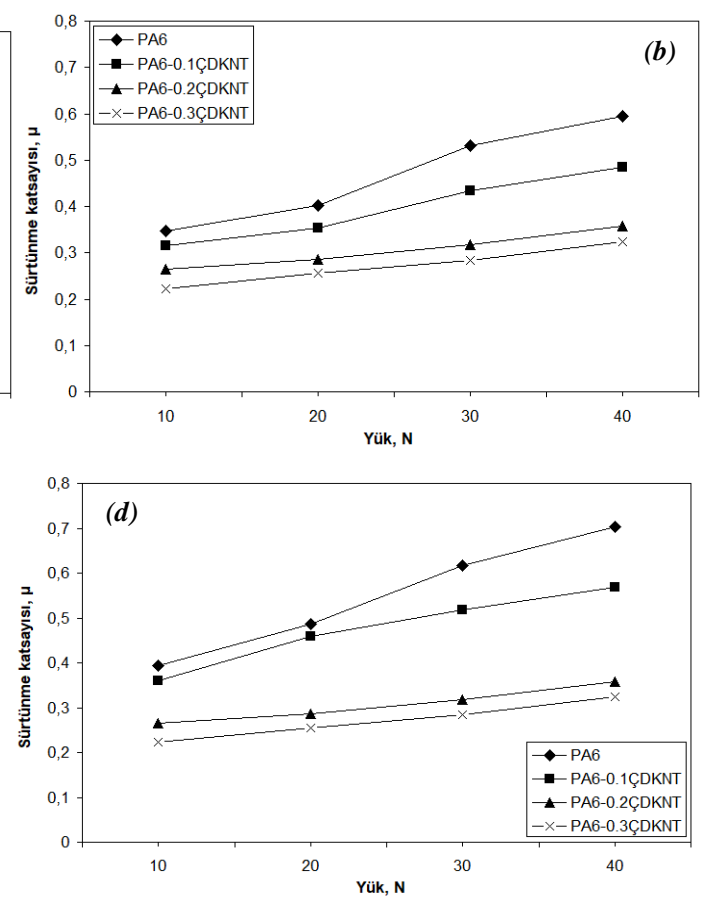

katkısız PA6 polimerinde elde edilirken, en düşük sürtünme katsayısı $0,4 \mathrm{~m} / \mathrm{s}$ kayma hızında, $10 \mathrm{~N}$ yük altında $0,2231 \mu$ değeri ile PA6-\%0,3ÇDKNT nanokompozitinde elde edilmiştir.

$40 \mathrm{~N}$ yük ve $0,4 \mathrm{~m} / \mathrm{s}$ kayma hızı altında 0,4174 $\mu$ olan sürtünme katsayısı, $\% 0,1$ ÇDKNT ilavesi ile \%36 artmıştır. PA6 polimerine eklenen katkı miktarı artıkça ( $\% 0,2 ; 0,3)$ PA6 nanokompozitlerin, artan kayma hızına bağlı olarak sürtünme katsayıları artmıştır. Benzer bir çalışma da Sirong ve arkadaşları (2007) tarafından yapılmıştır. PA66 matris malzemeye farklı oranlarda nano katkı ve uyumlaştırıcı olarak stiren-etilen-butilenstiren aş11 maleik anhidrit (SEBS-g-MA) ilave ederek hazırlamış oldukları nanokompozitlerin aşınma davranışlarını incelemişlerdir. Çalışma sonucunda, farklı oranlarda nano katkı ilavesi ile kayma hızı arttıkça sürtünme katsayısının arttı̆ını belirtmişlerdir. 

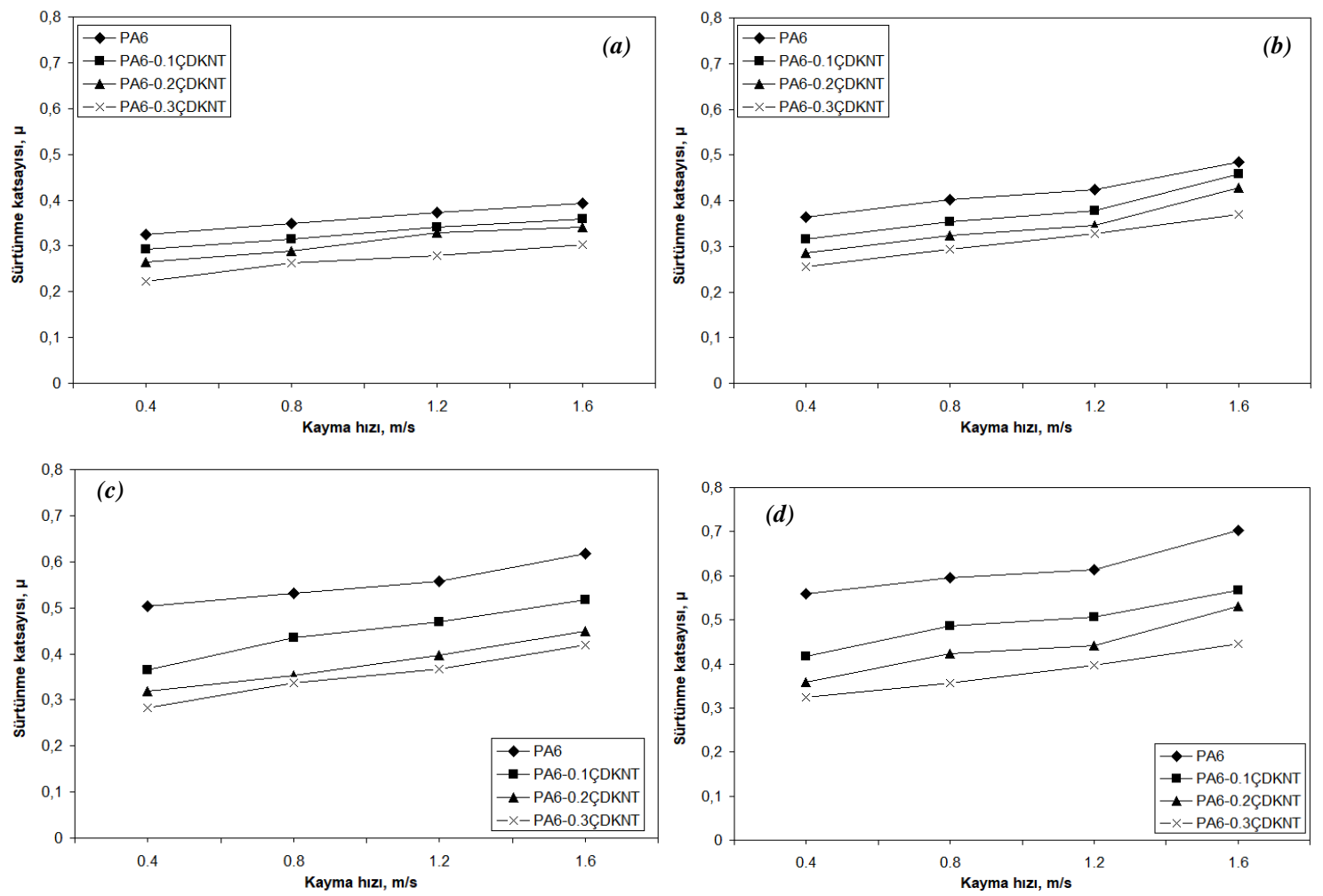

Şekil 8. PA6 ve PA6 nanokompozitlerin sürtünme katsayısı-kayma hızı ilişkisi: a)10 N, b) $20 \mathrm{~N}, \mathrm{c}) 30 \mathrm{~N}, \mathrm{~d}) 40 \mathrm{~N}$.

Şekil 9'da katkısız PA6 polimeri ile \%0,1; $\% 0,2$ ve $\% 0,3$ ÇDKNT katkı1ı PA6 nanokompozitlerinin $10-40 \mathrm{~N}$ yük altında kayma hızlarına bağlı olarak aşınma oranlarındaki değişim verilmiştir. Genel olarak şekiller incelendiğinde yükün artması ile aşınma oranlarının azaldığı belirlenmiştir. Katkısız PA6 polimeri, 0,4 m/s kayma hızında uygulanan yükün 10 N'dan 40 N'a arttırılması ile aşınma oranı \%165 azalmıştır. PA6 polimerine eklenen $(\% 01 ; \% 0,2$ ve $\% 0,3)$ ÇDKNT katkısı ise aşınma oranlarını \%160, $\% 372$ ve $\% 300$ oranında azaltmıştır. PA6 ve nanokompozitlerin $1,2 \mathrm{~m} / \mathrm{s}$ kayma hızındaki aşınma oranları incelendiğinde benzer sonuçlar gözlenmiştir. Uygulanan yük arttıkça aşınma miktarı azalmıştır. Katkısız PA6 polimerinin $10 \mathrm{~N}$ yük altında $2,212 \mathrm{E}^{-13} \mathrm{~m}^{2} / \mathrm{N}$ olan aşınma değeri yükün 40 N'a çıkartılması ile birlikte \%131 oranında azalarak 9,513 $\mathrm{E}^{-14}$ $\mathrm{m}^{2} / \mathrm{N}$ elde edilmiştir. PA6 polimerine ilave edilen ÇDKNT katkının aşınma oranı üzerindeki etkisi incelendiğinde ise artan ÇDKNT miktarına bağlı olarak aşınma oranının azaldığ 1 belirlenmiştir. $1,2 \mathrm{~m} / \mathrm{s}$ kayma hızında ve $20 \mathrm{~N}$ yük altında, katkısız PA6 polimerine ilave edilen $\% 0,1 ; \% 0,2$ ve $\% 0,3$ oranlarındaki ÇDKNT katkısı, aşınma oranlarını $\% 36, \% 87,5$ ve $\% 127$ azaltmıştır. Brian ve arkadaşları (2009), çalışmalarında benzer sonuçlar elde etmişlerdir. KNT miktarı arttıkça aşınma değerlerinin azaldığ 1 belirtilmiştir. Liu ve Chen (2000), ise matris malzemesine ilave edilen nano parçacıkların, bir film tabakası oluşturarak aşınma direncini arttığını belirtmişlerdir. 

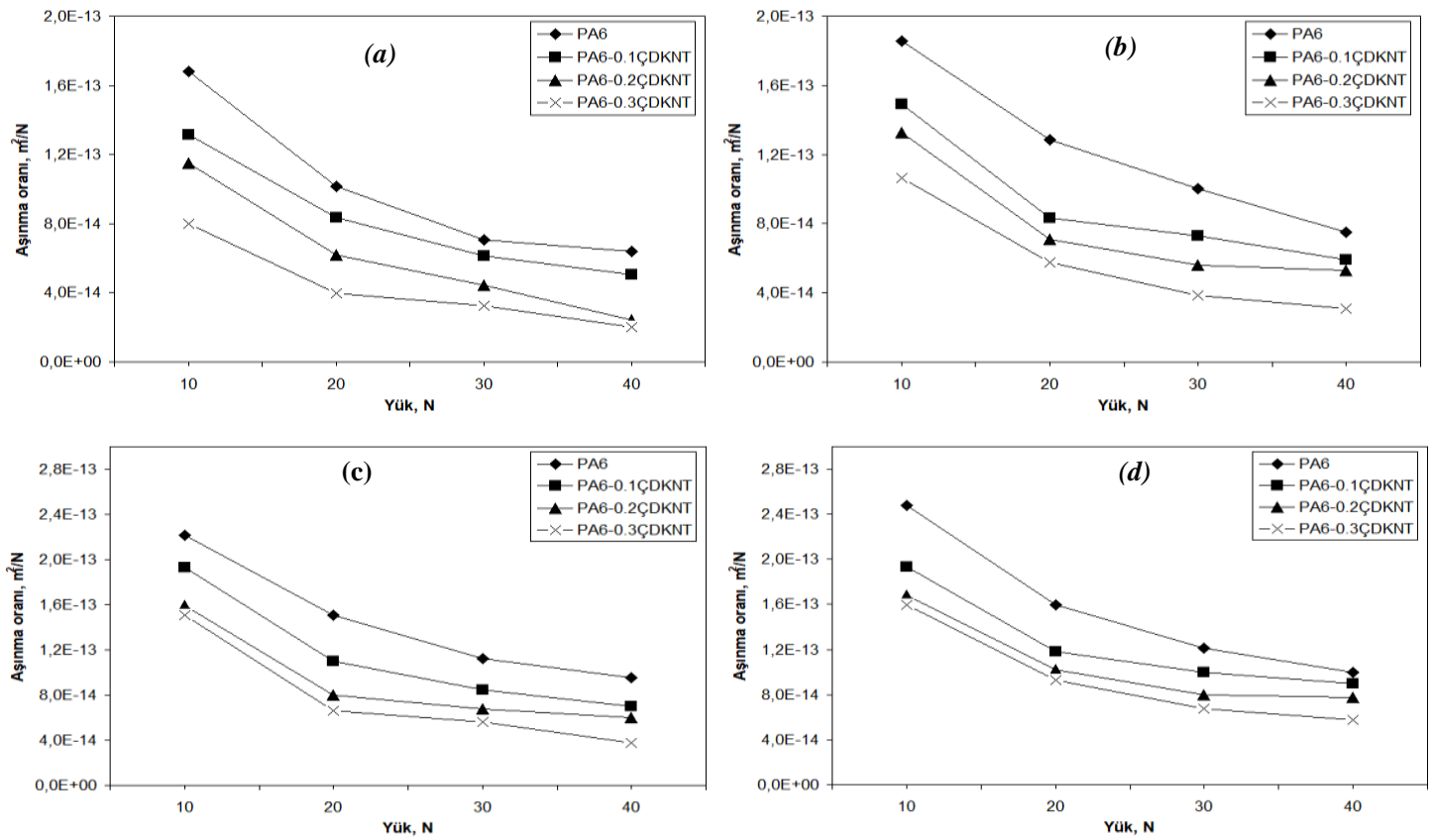

Şekil 9. PA6 ve PA6 nanokompozitlerin aşınma oranı-yük ilişkisi: a) 0,4 m/sn, b) 0,8 m/sn, c) $1,2 \mathrm{~m} / \mathrm{sn}, \mathrm{d}) 1,6 \mathrm{~m} / \mathrm{sn}$.
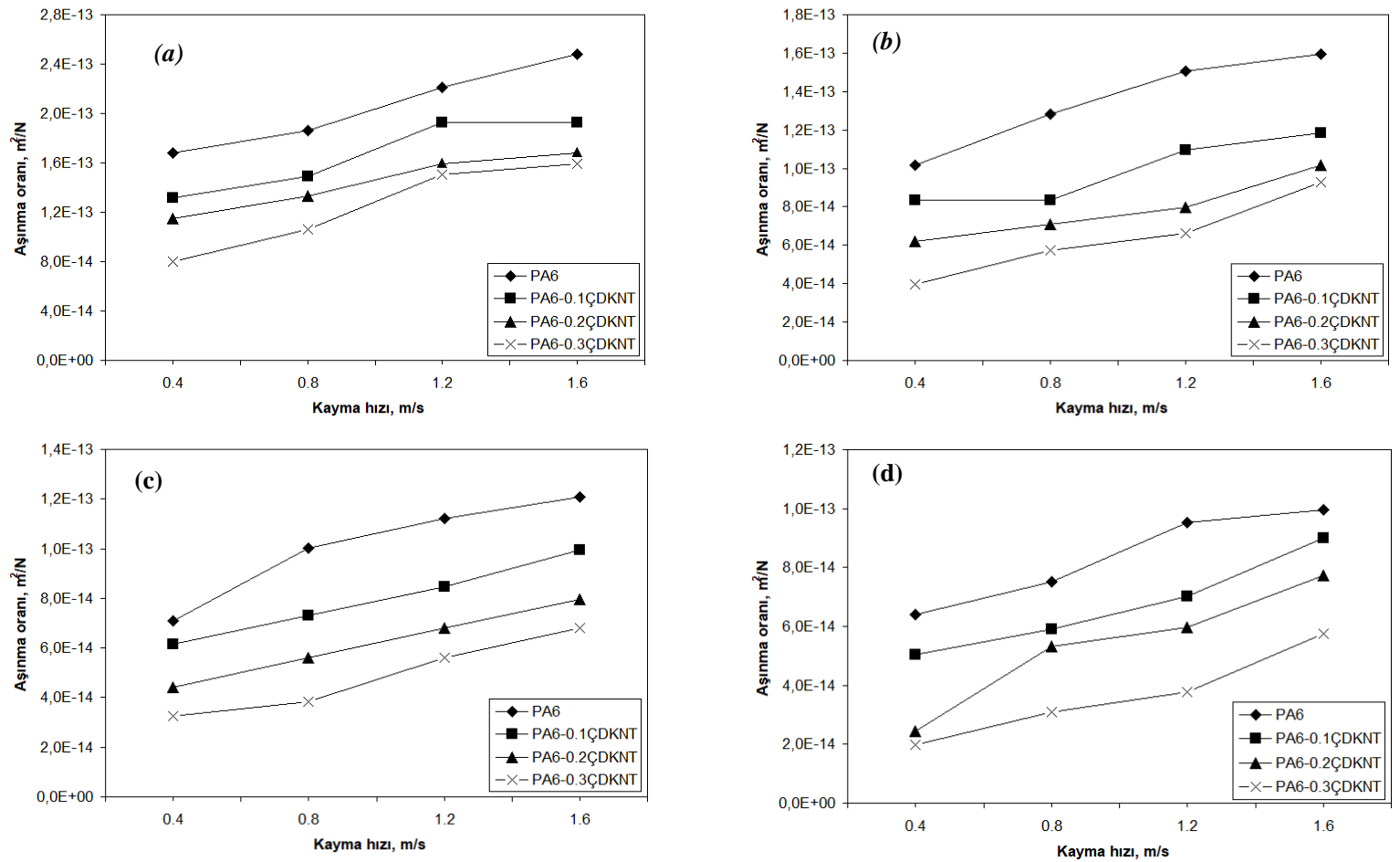

Şekil 10. PA6 ve PA6 nanokompozitlerin aşınma oranı-kayma hızı ilişkisi: a)10 N, b)20N, c)30 $\mathrm{N}, \mathrm{d}) 40 \mathrm{~N}$.

Şekil 10'da katkısız PA6 polimeri ile \%0,1; incelendiğinde, kayma hızının artması ile $\% 0,2 ; \quad \% 0,3$ ÇDKNT ilaveli PA6 aşınma oranı artmıştır. Katkısız PA6 polimeri nanokompozitlerin 0,$4 ; 0,8 ; 1,2$ ve $1,6 \mathrm{~m} / \mathrm{sn}$ için $0,4 \mathrm{~m} / \mathrm{s}$ kayma hızında $10 \mathrm{~N}$ yük altındaki kayma hızları altındaki aşınma oranı-kayma aşınma oranı $\% 47$ artmıştır. PA6 polimerine hızı ilişkisi verilmiştir. Genel olarak şekiller eklenen 0,1 ÇDKNT ilavesi ile 10 N yük 
altında kayma hızı $0,4 \mathrm{~m} / \mathrm{s}^{\prime}$ den $1,2 \mathrm{~m} / \mathrm{s}^{\prime}$ ye çıkartıldığında ise aşınma oranı $\% 46$ artmıştır. Xia ve arkadaşları (2004) da yaptıkları çalışmada, KNT katkısı ile aşınma direncinde artış olduğunu belirtmişlerdir. Uygulanan kayma hızı ve yük aralıklarında en düşük aşınma oranı $0,4 \mathrm{~m} / \mathrm{s}$ kayma hızı ve $40 \mathrm{~N}$ yük altında PA-0,3ÇDKNT nanokompozitinde elde edilirken en yüksek aşınma oran $1,6 \mathrm{~m} / \mathrm{s}$ kayma hızı ve $10 \mathrm{~N}$ yük altında PA6 polimerinde elde edilmiştir.

\section{Sonuçlar}

Farklı oranlarda ÇDKNT katkılı PA6 polimerinin termal, termo-mekanik ve tribolojik özelliklerinin incelendiği çalışmada aşağıdaki sonuçlar elde edilmiştir.

1) PA6 polimerine ilave edilen ÇDKNT ile PA6 polimerinin ergime sicaklı̆g $225{ }^{\circ} \mathrm{C}$ civarında sabit kalırken kristallenme oranlarının arttı̆̆ belirlenmiştir.

2) PA6 polimerinin $\% 24,78$ olan kristallenme oranı $\% 0,1 ; \% 0,2$ ve $\% 0,3$ ÇDKNT ilave edilmesi ile $\% 25,07 ; \% 28,51$ ve $\% 25,39$ oranlarında elde edilmiştir.

3) PA6 polimerinin $43,2{ }^{\circ} \mathrm{C}$ olan camsı geçiş sıcaklığı farklı oranlarda ÇDKNT ilave edilmesiyle 48,$4 ; 59,9$ ve $60,2{ }^{\circ} \mathrm{C}$ olarak elde edilmiştir.

4) PA6 polimerine ilave edilen farklı oranlardaki ÇDKNT katkısı PA6 polimerinin depolama modülünü ve kayıp modülünü artırmıştır.

5) Uygulanan yükün ve kayma hızının artmasıyla, sürtünme katsayısının arttığ gözlenmiştir.

6) PA6 polimerine ilave edilen ÇDKNT sürtünme katsayısını azaltmıştır. En büyük azalma tüksek ÇDKNT ilavesinde elde edilmiştir.

7) Uygulanan kayma hızı ve yük arasındaki en yüksek sürtünme katsayısı 1,6 m/s kayma hızı ve $40 \mathrm{~N}$ yük altında $0,7026 \mu$ değeri ile katkısız PA6 polimerinde elde edilirken, en düşük sürtünme katsayısı $0,4 \mathrm{~m} / \mathrm{s}$ kayma hızında, $10 \mathrm{~N}$ yük altında $0,2231 \mu$ değeri ile PA6-\%0,3ÇDKNT nanokompozitinde elde edilmiştir.

8) Yükün artması ile aşınma oranı azalırken kayma hızının artması ile aşınma oranı artmıştır.

9) Uygulanan kayma hızı ve yük aralıklarında en düşük aşınma oranı $0,4 \mathrm{~m} / \mathrm{s}$ kayma hızı ve 40 N yük altında PA-0,3ÇDKNT nanokompozitinde elde edilirken en yüksek aşınma oranı $1,6 \mathrm{~m} / \mathrm{s}$ kayma hızı ve $10 \mathrm{~N}$ yük altında PA6 polimerinde elde edilmiştir.

\section{Teşekkür}

Yazarlar, Dumlupınar Üniversitesi, Bilimsel Araştırma Projeleri Başkanlığına desteklerinden dolayı teşekkür eder. (Proje No: DPÜ-BAP 2016-90), Türkiye.

\section{Kaynaklar}

Aparna, S., Purnima, D., Adusumalli, R.B. (2018). "Effect of Compatibilizer on the Properties of Polyamide 6 Blend Based Carbon Fiber Reinforced Composites", Fibers and Polymers, 19(6), 1335-1346.

Araujo, E.M., Damiao, A.M., Paz, R.A., Medeiros, V.N., Melo, T.J.A., Lira, H.L. (2011). "Polyamide 6 Nanocomposites with Inorganic Particles Modified with Three Quaternary Ammonium Salts", Journal Materials, 4, 1956-1966.

Aso, O., Eguiaz A.J., Nazabal, J. (2007). “The Influence of Surface Modification on the Structure and Properties of a Nanosilica Filled Thermoplastic Elastomer Composites", Science and Technology, 67, 2854-2863.

Bose, S., Bhattacharyya, A.R., Khare, R.A., Kulkarni, A.R., Patro, T.U., Sivaraman, P. 
(2008). "Tuning the Dission of Multiwall CNTs in Co-Continuous Polymer Blends, A Generic Approach", Nanotechnology, 19(33), 3304-3312.

Brian, B., Johnson, M.H., Santare, J.E., Novotny, S., Advani, G. (2009). "Wear Behavior of Carbon Nanotube High Density Polyethylene Composites", Mechanics of Materials, 41, 1108-1115.

Duxin, L., Ying, X., Wenjuan, L., Yilan, Y. and Xin, D. (2013). "Tribological and Mechanical Behaviors of Polyamide 6/Glass Fiber Composite Filled with Various Solid Lubricants", The ScientificWorld Journal, 19.

Esmizadeh, E., Irani, A., Naderi, G., Ghoreishy, M. H. R., Dobious, C. (2018). "Effect of Carbon Nanotube on PA6/ECO Composites.Morphology Development, Rheological and Thermal Properties", Journal of Applied Polymer Science, 135(12), 45977.

Hassani, J., Mohd, I.Z.A., Mohamed, A.R. (2013). "Preparation and Characterization of Polyamide 6 Nanocomposites Using MWCNTs Based on Bimetallic Co-Mo/MgO catalyst", Polymer Letters, 8, 177-186.

Hongfu, L., Yanfei, Z., Yang, W., Boming, Z. (2018). "Effects of Thermal Histories on Carbon Fiber/Polyamide 6 Microcomposite Load Transfer Efficiency:Crystallization, Modulus, and Measurement", Polymer Composites, 39(1), 102-109.

Hou, W., Tang, B., Lingling, L., Sun, J., Wang, J., Qin, C., Dai, L. (2013). "Preparation and Physico-Mechanical Properties of AmineFunctionalized Graphene/Polyamide 6 Nanocomposite Fiber as a High
Performance", The Journal RSC Advances, 4, 4848-4855.

Hyo Jin, A., Jung Soo, K., Ki-Young, K., Dae Young, L. and Dong Hyun, K. (2014). "Mechanical and Thermal Properties of Long Carbon Fiber-reinforced Polyamide 6 Composites", Fibers and Polymers, 15(11), 2355-2359.

Jian, L. (2011). "The effect of PTFE on the mechanical and friction and wear properties of GF/PA6 composites", Advanced Materials Research, 284-286, 2370-2373.

Jin, Z.X., Pramoda, K.P., Goh, S.H. (2001). "Dynamic Mechanical Behaviour of Melt Mixed Polymer Nanocomposite", Chemical Physics Letter, 337, 41-47.

Kanapitsas, A. and Tsonos, C. (2009). "Study of Electrical/Dielectric and Thermomechanical Properties of PolymerCarbon Nanotubes Nanocomposites", Research Gate, 45, 75-81.

Kaştan, A., (2015). PA6/PE/Nano-kil Kompozitlerinin İncelenmesi, Doktora Tezi, Afyon Kocatepe Üniversitesi Fen Bilimleri Enstitüsü.

Kumar, S.S. and Kanagaraj, G. (2016). "Investigation on Mechanical and Tribological Behaviors of PA6 and GraphiteReinforced PA6 Polymer Composites", Arabian Journal for Science and Engineering, 41, 4347-4357.

Lee, S.M., Shin, M.W., Jang, H. (2014). "Effect of Carbon-Nanotube Length on Friction and Wear of Polyamide 66 Nano composites", Wear, 32, 103-110.

Liu, P.I.Y., Shen, L., Chow, S.Y., Zhang, W.D. (2004). Morphology and Mechanical 
Properties of Multiwalled Carbon Nanotubes Reinforced Nylon-6 Composites", Macromolecules, 19, 7214-7222.

Liu, W., Chen, S., (2000). “An Investigation of the Tribological Behaviour of Surface Modified $\mathrm{ZnS}$ Nanoparticles in Liquid Parafin", Wear, 238, 120-124.

Mahmood, N., Islam, M., Hameed, A., Saeed, S. (2013). "Polyamide 6/Multiwalled Carbon Nanotubes Nanocomposites with Modified Morphology and Thermal Properties", Polymers, 5(4), 1380-1391.

Marini, J. and Suman, B.R.E. (2017). "Optical Properties of Blown Films of PA6/MMT Nanocomposites", Materials Research, 5360 .

Sirong, Y., Zhongzhen, Y., Wing, M.Y. (2007). "Effects of SEBS-g-MA on Tribological Behaviour of Nylon 66 organoclay Nanocomposites", Tribology International, 40(5), 855-862.

Sorrentino, A., Vertuccio, L., Vittoria V., (2010). "Influence of Multi-walled Carbon Nanotubes on the $\beta$ form Crystallization of Syndiotactic Polystyrene at Low Temperature", Polymer Letters, 4, 339-345.

Suresha, B.N., Kumar, R., Venkataramareddy, M., Jayaraju, T. (2010). "Role of Micro Nano Fillers on Mechanical and Tribological Properties of Polyamide 66 Polypropylene Composites", Materials Design, 31, 1993-2000.

Szymczyk, A., Roslaniec, Z., Zenker, C., Senderek, E., Funari S. (2011). "Crystallization Behaviour of Poly Trimethylene Terephthalate SWNT Nanocomposites", Express Polymer Letters, 5, 977.
Xia, H., Wang, Q., L1, K.H. (2004). "Preparation of Polypropylene Carbon Nanotube Composite Powder with a solidstate Mechanochemical Pulverization Process", Journal of Applied Polymer Science, 93, 378-386.

Xu, Q., Xiaohong, L., Fangfei, C., Zhijun, Z. (2014). "Improving the Mechanical Properties of Polyamide 6-Nanosilica Nanocomposites by Combining Masterbatch Technique with in situ Polymerization", Journal of the Brazilian Chemical Society, 25(7), 1218-1225.

Yang, Z., Dong, B., Huang, Y., Liu, L., Yan, F.Y., Li, H.L. (2005). "A Study on Carbon Nanotubes Reinforced Poly Methyl Methacrylate Nanocomposites", Materials Letters, 59, 2128-2132.

Yisha, Y., Duxin, L., Gaojie, S., Qilong, L. and Yue, C. (2017). "Improved thermal and mechanical properties of carbon fiber filled polyamide 46 composites", Journal of Polymer Engineering, 37(4), 345-353. 